\title{
REVIEW
}

\section{Esophageal and transpulmonary pressure in the clinical setting: meaning, usefulness and perspectives}

\begin{abstract}
Tommaso Mauri ${ }^{1}$, Takeshi Yoshida ${ }^{2,3,4}$, Giacomo Bellani ${ }^{5}$, Ewan C. Goligher ${ }^{6,712}$, Guillaume Carteaux ${ }^{8,9}$, Nuttapol Rittayamai ${ }^{10,11,12}$, Francesco Mojoli'13, Davide Chiumello 1,14, Lise Piquilloud ${ }^{15,16}$, Salvatore Grasso ${ }^{17}$, Amal Jubran ${ }^{18}$, Franco Laghi ${ }^{18}$, Sheldon Magder ${ }^{19}$, Antonio Pesenti ${ }^{1,14}$, Stephen Loring ${ }^{20}$, Luciano Gattinoni ${ }^{1,14}$, Daniel Talmor ${ }^{20}$, Lluis Blanch ${ }^{21}$, Marcelo Amato ${ }^{22}$, Lu Chen ${ }^{11,12}$, Laurent Brochard ${ }^{11,12^{*}}$, Jordi Mancebo ${ }^{23}$ and the PLeUral pressure working Group (PLUG_Acute Respiratory Failure section of the European Society of Intensive Care Medicine)
\end{abstract}

(C) 2016 Springer-Verlag Berlin Heidelberg and ESICM

\begin{abstract}
Purpose: Esophageal pressure (Pes) is a minimally invasive advanced respiratory monitoring method with the potential to guide management of ventilation support and enhance specific diagnoses in acute respiratory failure patients. To date, the use of Pes in the clinical setting is limited, and it is often seen as a research tool only.

Methods: This is a review of the relevant technical, physiological and clinical details that support the clinical utility of Pes.

Results: After appropriately positioning of the esophageal balloon, Pes monitoring allows titration of controlled and assisted mechanical ventilation to achieve personalized protective settings and the desired level of patient effort from the acute phase through to weaning. Moreover, Pes monitoring permits accurate measurement of transmural vascular pressure and intrinsic positive end-expiratory pressure and facilitates detection of patient-ventilator asynchrony, thereby supporting specific diagnoses and interventions. Finally, some Pes-derived measures may also be obtained by monitoring electrical activity of the diaphragm.
\end{abstract}

Conclusions: Pes monitoring provides unique bedside measures for a better understanding of the pathophysiology of acute respiratory failure patients. Including Pes monitoring in the intensivist's clinical armamentarium may enhance treatment to improve clinical outcomes.

Keywords: Esophageal pressure, Acute respiratory failure, Acute respiratory distress syndrome, Physiologic monitoring, Mechanical ventilation

\footnotetext{
*Correspondence: BrochardL@smh.ca

${ }^{11}$ Keenan Research Centre, Li Ka Shing Knowledge Institute, St. Michael's Hospital, Toronto, Canada

Full author information is available at the end of the article

The aims and members of the PLUG Working Group are listed in the electronic supplementary material..
}

\section{Introduction}

Esophageal pressure (Pes) measurement is a minimally invasive monitoring method used to assess respiratory mechanics. In acute respiratory failure patients, Pes tracings can be used to individually understand, define and evaluate the pathophysiological mechanisms of respiratory failure, to titrate invasive and non-invasive respiratory and pharmacological support and to follow the patient's 
clinical course. Nonetheless, Pes monitoring is still seldom used in the clinical setting; rather, it remains widely seen as a research tool. In an effort to clarify the usefulness of Pes measurement in the clinical setting, we address here the relevant technical, physiological and clinical details of this monitoring method to facilitate a better understanding of the information that can be obtained by bedside Pes measurement. Two recent reviews have dealt with the same topic $[1,2]$. In our review we include updated information from the most recent literature and provide clinical threshold values for transpulmonary pressure $\left(\mathrm{P}_{\mathrm{L}}\right)$ as reference to guide ventilation settings. We also include an extensive analysis on both the clinical value of transmural pulmonary vascular pressure measurements and the correlation between Pes and the electrical activity of the diaphragm. A number of case-scenarios in which Pes monitoring could be of help at the bedside are described (Table 1), and a video on the practical use of the technique is provided in the Electronic Supplementary Material (ESM).

\section{Measurement of Pes}

\section{The catheter-balloon system: positioning and calibration}

The most common technique for measuring Pes employs an esophageal balloon filled with air, connected to a long thin catheter. The first generation of custom-made esophageal balloons was primarily used for research purposes; since then, several types of second-generation balloons have been developed in the last decade which are currently available for bedside clinical use. Esophageal balloon catheters can be connected to dedicated monitoring devices, to accessory pressure ports of mechanical ventilators or to pressure transducers of multi-parametric monitors.

To obtain reliable Pes measurements, the esophageal balloon must be placed in an appropriate position and the balloon inflated with an adequate volume of air. An underfilled balloon does not properly transmit the Pes, whereas an over-filled balloon can over-estimate the pressure [3]. The "optimal" air filling volume depends on the design, dimensions, geometry and material of the esophageal balloon, which in turn affect its mechanical properties. The six most common commercially available esophageal catheters have recently been tested in vitro at an external pressure ranging from 0 to $30 \mathrm{cmH}_{2} \mathrm{O}$. All of the catheters tested were found to accurately measure the surrounding pressure, but the optimal filling volume differed substantially among the catheters [4]. In addition, the minimum volume required for valid measurements was greater than those recommended previously and was dependent on the surrounding pressure [4]. Another study similarly found that the filling volume varied with the tested catheters and that the volume should be increased in the presence of high external pressure [5]. Physicians must account for these technical issues. In clinical practice, a simple method to determine the optimal filling volume is to progressively inflate the balloon, within the catheterspecific adequate range of filling volumes, finally selecting the lowest volume associated with the largest tidal swings (inspiratory to expiratory) of Pes $[4,6]$.

\section{Method to insert the catheter and validate Pes during mechanical ventilation}

A video describing the insertion and interpretation of the Pes is provided in the ESM. After deflating the esophageal balloon and securing it with a three-way stopcock, it is introduced into the esophagus transorally or transnasally. The esophageal catheter is then gently advanced to a depth of about $55 \mathrm{~cm}$ to reach the stomach and inflated with the minimum recommended volume $[4,5]$. The intragastric position of the catheter is confirmed by a positive pressure deflection during gentle external manual epigastric compression. Subsequently, the catheter is progressively withdrawn into the esophagus. Esophageal positioning is suggested by the appearance of cardiac artifacts on the pressure tracings and by the change from intra-abdominal to intra-thoracic pressure patterns. Placement of the esophageal balloon in the lower two thirds of the intrathoracic esophagus has been suggested as a way to limit possible pressure artifacts due to non-homogeneous esophageal compression by external structures [7].

When spontaneous inspiratory efforts are present, the conventional test to validate the Pes measurement is to compare the simultaneous negative deflections of airway and esophageal pressures during an end-expiratory occlusion maneuver (the so-called Baydur test) [3, 8]. During the occluded inspiration, the change in airway $(\Delta$ Paw) and esophageal $(\Delta$ Pes) pressure should be almost identical because there is no change in lung volume and, thus, no change in $\mathrm{P}_{\mathrm{L}}$. When the $\Delta \mathrm{Pes} / \Delta \mathrm{Paw}$ ratio is within $0.8-1.2$, the Pes measurement is considered to be reliable. Otherwise, the catheter should be repositioned and/or the balloon volume should be re-checked $[3,9]$. In deeply sedated patients with or without paralysis, external manual compressions on the rib cage should be applied during an expiratory pause and simultaneous positive deflections of airway and esophageal pressures compared (positive pressure occlusion test) [1].

For the same esophageal catheter position, the Baydur and the positive pressure occlusion tests provide similar changes in airway and esophageal pressures [10]. The absolute value can be significantly higher when the esophageal balloon is placed in the lower third of the esophagus, compared to the middle one, due to the higher superimposed pressure generated by the heart and the lung. Moreover, the pressure generated by the esophageal wall as a reaction to balloon filling may increase the absolute value of Pes above the pleural pressure $\left(\mathrm{P}_{\mathrm{p} 1}\right)$ 


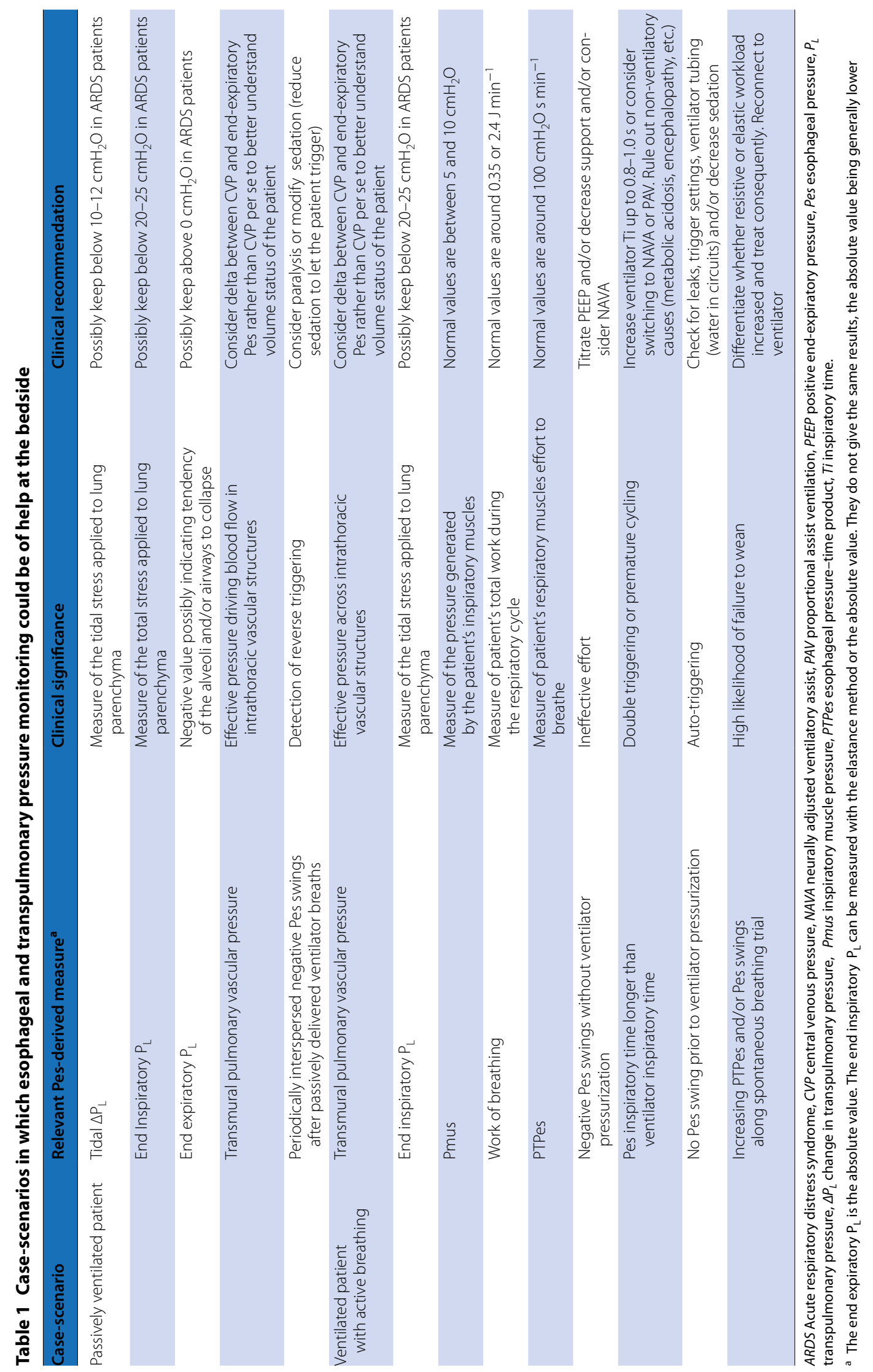


value. Therefore, a dedicated calibration procedure has been recently described that removes this artifact, resulting in the improved use of absolute values of Pes, especially when large-volume balloons are used [6]. While the presence of a nasogastric tube does not seem to significantly affect Pes measurement [11], nasogastric tubes equipped with an esophageal balloon are now available [4].

\section{Transpulmonary pressure}

Changes in transpulmonary pressure during mechanical ventilation: a measure of stress on the acute respiratory distress syndrome-injured lung

The clinical use of Pes measurement allows the estimation of $\mathrm{P}_{\mathrm{L}}$ as the difference between Paw and $\mathrm{P}_{\mathrm{pl}}$ (estimated as Pes), which drives ventilation of the lung (including the airways). Here, we first look at the pathophysiological significance of the changes in $\mathrm{P}_{\mathrm{L}}$ induced by ventilation.

The airway driving pressure (the change between endexpiratory total pressure to end-inspiratory plateau pressure) delivered by the ventilator to inflate the respiratory system $(\Delta \mathrm{Paw})$ may be divided in two components: one to insufflate the lung, called change in transpulmonary pressure $\left(\Delta \mathrm{P}_{\mathrm{L}}\right)$, and one to move the chest wall, called change in pleural pressure $\left(\Delta \mathrm{P}_{\mathrm{p} l}\right)$, where $\Delta \mathrm{P}_{\mathrm{pl}}$ equals the changes of the esophageal pressure $(\Delta \mathrm{Pes})[12,13]$ :

$$
\Delta \mathrm{Paw}=\Delta P_{\mathrm{L}}+\Delta P_{\mathrm{pl}}
$$

In this section, we will refer to tidal $\Delta \mathrm{P}_{\mathrm{L}}$, ignoring for sake of simplicity the fraction of $\Delta \mathrm{P}_{\mathrm{L}}$ due to positive endexpiratory pressure (PEEP). As the changes in lung volume and chest wall volume are deemed to be identical, the expression above may be written as:

$$
\Delta \text { Paw } / \Delta V=\Delta P_{\mathrm{L}} / \Delta V+\Delta P_{\mathrm{pl}} / \Delta V
$$

The elastance of the respiratory system (Ers) is equal to the lung elastance $\left(E_{L}\right)$ plus the chest wall elastance $\left(E_{c w}\right)$. Since Ers $=\Delta \mathrm{Paw} / \Delta \mathrm{V}$ and $\mathrm{E}_{\mathrm{L}}=\Delta \mathrm{P}_{\mathrm{L}} / \Delta \mathrm{V}$, the following expression may be derived:

$$
\Delta P_{\mathrm{L}}=\Delta \mathrm{Paw} \cdot\left(E_{\mathrm{L}} / \text { Ers }\right)
$$

This equation tells us that the pressure applied to the lung for a given driving pressure depends on the ratio between the $E_{L}$ to the Ers, irrespective of their absolute values. In normal subjects, the typical value of $E_{L} / E r s$ is equal to 0.5 . In intensive care patients without respiratory or abdominal problems this ratio averages $\approx 0.7$; in acute respiratory distress syndrome (ARDS) patients it may range from 0.5 (or even lower) to 0.9. Given these values, in a patient ventilated with PEEP $10 \mathrm{cmH}_{2} \mathrm{O}$ and a plateau pressure of $30 \mathrm{cmH}_{2} \mathrm{O}$, the tidal $\Delta \mathrm{P}_{\mathrm{L}}$ may range from $10 \mathrm{cmH}_{2} \mathrm{O}$ \{non-injurious, i.e. [ $\left(30 \mathrm{cmH}_{2} \mathrm{O}\right.$ plateau
Paw $-10 \mathrm{cmH}_{2} \mathrm{O}$ PEEP) $\left.\left.\times 0.5\right]\right\}$ to $18 \mathrm{cmH}_{2} \mathrm{O}$ \{highly "bio-traumatic", i.e. [ $\left(30 \mathrm{cmH}_{2} \mathrm{O}\right.$ plateau Paw $-10 \mathrm{cmH}_{2} \mathrm{O}$ $\mathrm{PEEP}) \times 0.9]\}$, as discussed further in this review [12] Thus, the lung protective ventilation strategy might be, theoretically, titrated to a "safe" tidal $\Delta \mathrm{P}_{\mathrm{L}}$ rather than to tidal volume [14].

When tidal $\Delta \mathrm{P}_{\mathrm{L}}$ is applied, it changes the lung volume ( $\Delta$ volume). The ratio between $\Delta$ volume and the pre-inflation lung volume $\left(\mathrm{V}_{0}\right)$ is called strain. The tissue molecules which compose the extracellular matrix develop a force opposing the tidal $\Delta \mathrm{P}_{\mathrm{L}}$, which is called stress. Stress and strain are nearly linearly related up to the total lung capacity. Therefore,

$$
\text { stress }=K \times \text { strain }
$$

meaning that

$$
\Delta P_{\mathrm{L}}=K \times \Delta V / V_{0}[12,15]
$$

The proportionality constant $K$ is called specific lung elastance and is the tidal $\Delta \mathrm{P}_{\mathrm{L}}$ value at which $\mathrm{V}_{0}$ doubles its size (without PEEP). In humans $K$ is around $12-13 \mathrm{cmH}_{2} \mathrm{O}$, which is substantially greater than other animal species [16, 17], and it seems to be similar in patients with ARDS and healthy subjects [15]. These concepts are summarized in ESM Fig. 1. As shown, when tidal $\Delta \mathrm{P}_{\mathrm{L}}$ approximates $20 \mathrm{cmH}_{2} \mathrm{O}$, part of the lung enters its total lung capacity region. In healthy animals, when ventilation occurs in this area, lethal ventilator-induced lung injury develops within $24 \mathrm{~h} \mathrm{[17].} \mathrm{In} \mathrm{clinical} \mathrm{prac-}$ tice, it is rare to reach these values of tidal $\Delta P_{\mathrm{L}}$. However, it must be remembered that in ARDS a substantial fraction of the lung includes inhomogeneities which act as stress raisers, with the possible effect of doubling the locally applied pressure [18]. Therefore, a tidal $\Delta \mathrm{P}_{\mathrm{L}}$ of $10 \mathrm{cmH}_{2} \mathrm{O}$-in the presence of stress raisers-may regionally increase transpulmonary and transalveolar pressure to $20 \mathrm{cmH}_{2} \mathrm{O}$.

While waiting for more definitive evidence, tidal $\Delta \mathrm{P}_{\mathrm{L}}$ should probably be kept below $15-20 \mathrm{cmH}_{2} \mathrm{O}$ in patients with homogeneous lung parenchyma (normal, postsurgical patients) and possibly below $10-12 \mathrm{cmH}_{2} \mathrm{O}$ in patients with inhomogeneous lung parenchyma (ARDS).

When respiratory muscle activity is present, then the active changes in $\mathrm{P}_{\mathrm{pl}}$ can dominate the $\mathrm{P}_{\mathrm{L}}$ changes driving ventilation.

\section{Transpulmonary pressure directly measured to guide mechanical ventilation in ARDS}

Measurement of Pes also allows estimation of the absolute value of $P_{L}$, measured as the Paw minus the $\mathrm{P}_{\mathrm{pl}}$ and clinically estimated as Paw-Pes. The alternative elastance-derived method for estimating $P_{\mathrm{L}}\left(\Delta P_{\mathrm{L}}=\Delta \mathrm{Paw} \cdot\left(E_{\mathrm{L}} /\right.\right.$ Ers $)$ was covered in the previous 


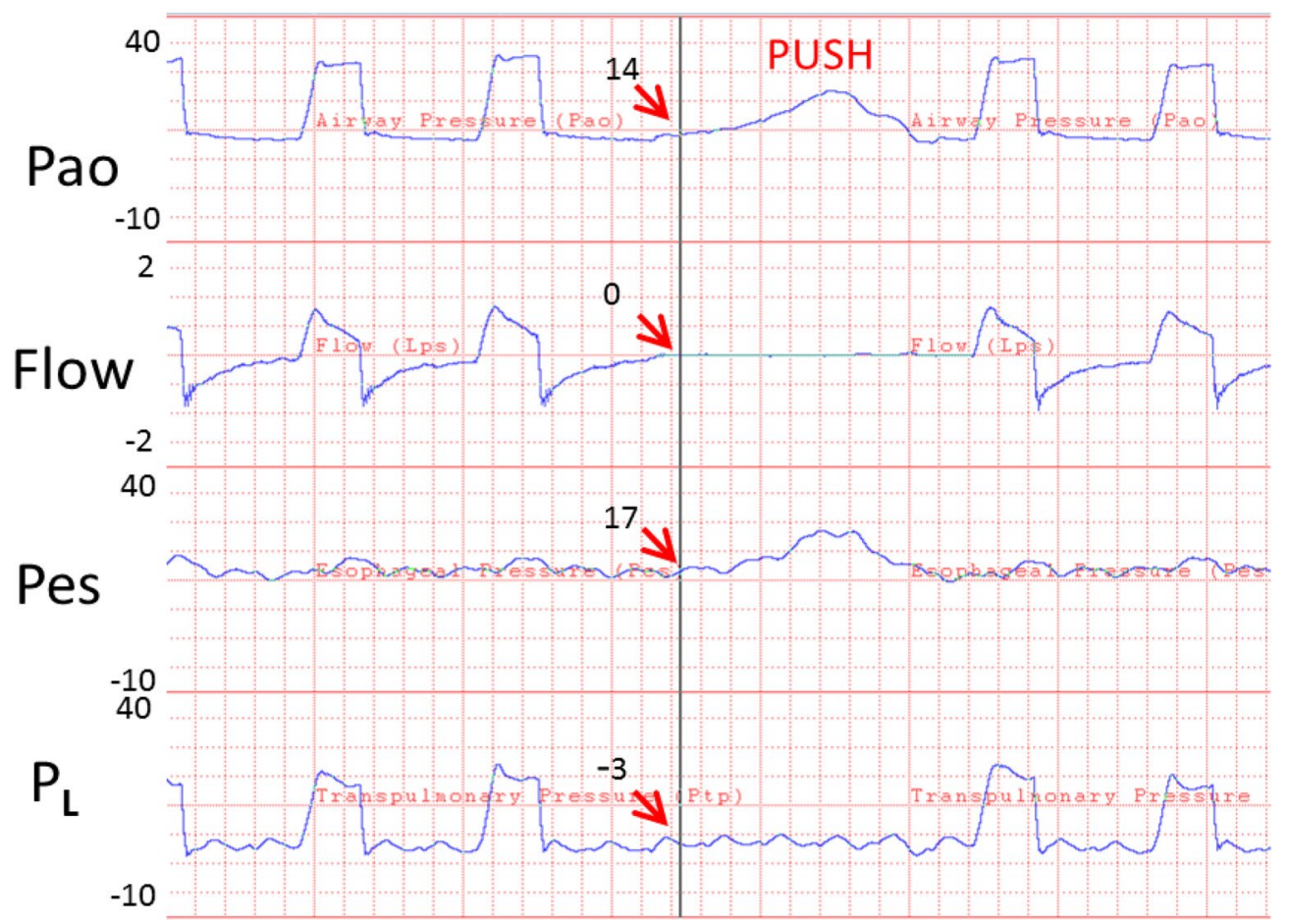

Fig. 1 Directly measured transpulmonary pressure in acute respiratory distress syndrome (ARDS). Airway opening pressure (Pao), flow (Flow), esophageal pressure $(P e s)$ and transpulmonary pressure $\left(P_{L}\right)$ in a patient with ARDS on mechanical ventilation. At the end-expiratory occlusion (cursor) a total positive end expiratory pressure (PEEP) of $14 \mathrm{cmH}_{2} \mathrm{O}$ and a Pes of $17 \mathrm{cmH}_{2} \mathrm{O}$ result in a $\mathrm{P} \mathrm{L}_{\mathrm{L}}$ of $-3 \mathrm{cmH}_{2} \mathrm{O}$. During the occlusion, a manual chest compression (PUSH) raises Pao and Pes equally, indicating adequate balloon placement in the chest

section. In patients breathing on non-invasive ventilation, $\mathrm{P}_{\mathrm{L}}$ is estimated using the pressure in the mask (Pmask-Pes). Due to the location of the esophagus in the supine position, an increase in Pes caused by mediastinal weight of 3-7 $\mathrm{cmH}_{2} \mathrm{O}$ may exist in that position: whether Pes is higher than $\mathrm{P}_{\mathrm{pl}}$ at the corresponding height in the chest is unclear [19]. Because $\mathrm{P}_{\mathrm{pl}}$ varies spatially in the chest, Pes cannot theoretically represent $\mathrm{P}_{\mathrm{pl}}$ over the entire lung. However, animal studies suggest that Pes represents well the pressure surrounding much of the lung [20].

In ARDS, ventilator settings are adjusted to reduce tidal overexpansion of the lungs by limiting tidal volume (and pressure) and to avoid repeated airspace collapse and derecruitment by maintaining adequate PEEP [21]. Pleural and intra-abdominal pressures vary widely and can be quite high in critical illness, regardless of chest wall compliance [22]. Therefore, a given PEEP applied by the ventilator could have varying effects on $\mathrm{P}_{\mathrm{L}}$. A clinical trial in ARDS patients compared PEEP adjusted to maintain a positive end-expiratory $\mathrm{P}_{\mathrm{L}}$ (Fig. 1) with PEEP levels specified in the ARDSNet low-tidal volume table [23]. The $P_{L}$ approach significantly improved oxygenation and compliance and showed a trend toward reduced mortality [23]. This rationale was confirmed in animals with lung injury and different degrees of Pes elevation due to chest wall restriction. Targeting a positive endexpiratory $\mathrm{P}_{\mathrm{L}}$ in chest-restricted animals maintained lung volume and lung compliance, reduced hypoxemia and decreased pulmonary edema, mechanical abnormalities, pro-inflammatory mediator release and histological signs of ventilator-induced lung injury [24].

Uncertainties of direct esophageal manometry include the spatial variation in $\mathrm{P}_{\mathrm{pl}}$ and the mediastinal weight that elevates Pes in the supine position [19]. As previously discussed, adequate filling and positioning of the balloon is important to obtain reliable measurements.

\section{Transmural vascular pressure}

Transmural pulmonary vascular pressures

The force distending vascular walls is called the transmural pressure (Ptm) and is determined by the difference between the pressure inside and outside of the vessel [25]. An increase in Ptm implies an increase in volume of the vessel. Since we are surrounded by atmospheric pressure (Patm), transducers are zeroed to Patm, and the pressure inside systemic vessels is the Ptm. For alveolar vessels, however, $\mathrm{P}_{\mathrm{pl}}$ (not Patm) surrounds the vascular 


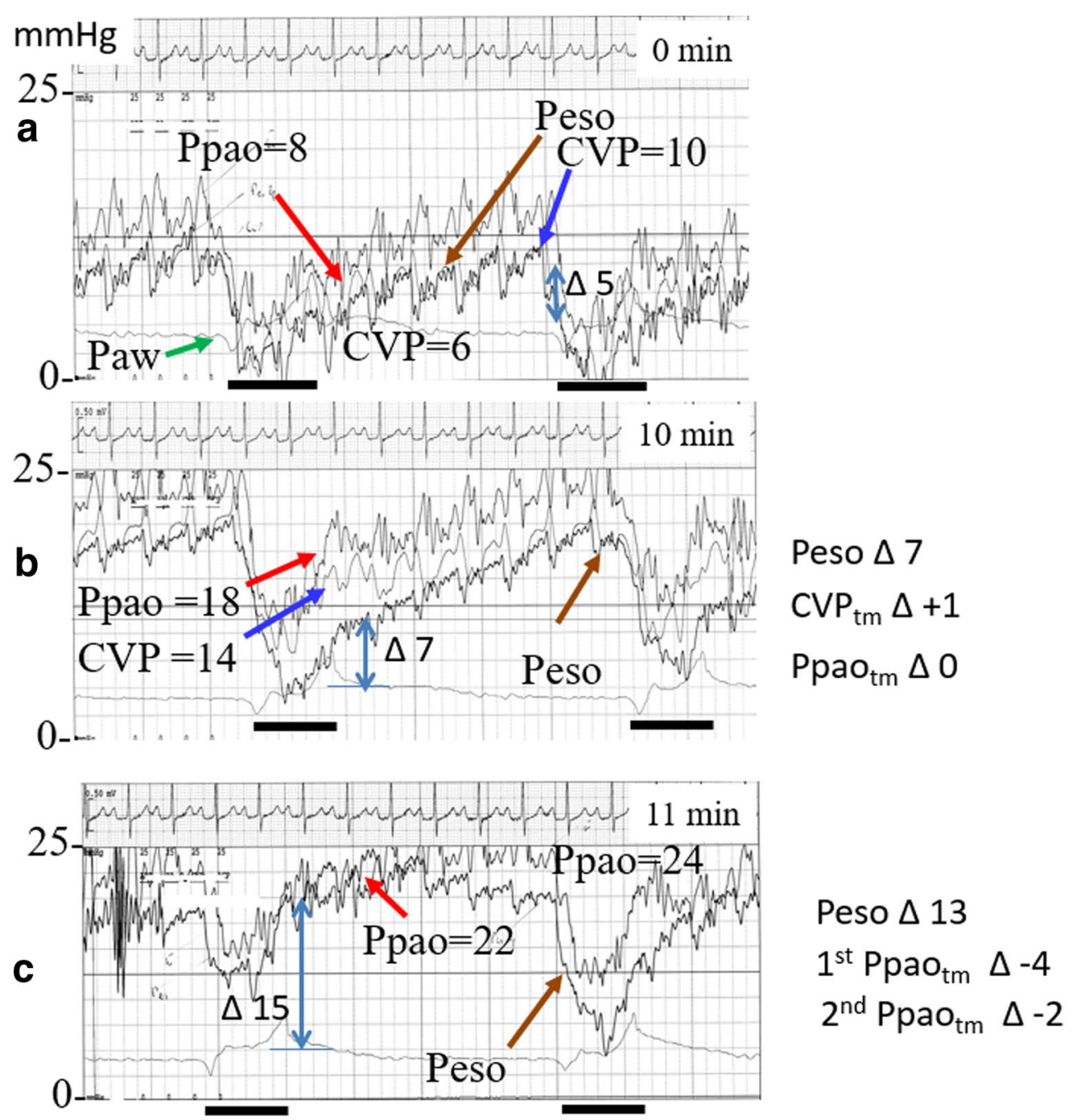

Fig. 2 Value of esophageal pressure (Peso)-derived transmural vascular pressure (Ptm). Examples of changing Ptm of the central venous pressure (CVP) and pulmonary artery occlusion pressure (Ppao) during pressure support. Black horizontal bars mark inspiration. Paw airway pressure. The subject has marked active expiration on all breaths. a CVP is $10 \mathrm{mmHg}$ at end-expirations (it is overlapping the Peso) but 6 mmHg at the start of expiration, which is the likely the Ptm. b 10 min later, CVP has increased to more than Peso, so that CVP $\mathrm{tm}_{\mathrm{tm}}$ ( $\mathrm{tm}$ transmural) has increased, likely indicating recruitment of abdominal volume from the active expiration. Ppao ${ }_{t m}$ did not change. $\mathbf{c} 1$ min later, only Ppao is shown. The Ppao has $_{\text {decreased }}$ with some recovery late in expiration. It is likely that the rise in pleural pressure $\left(P_{p l}\right)$ inhibited venous return with some later recovery because of the recruitment of abdominal volume. The subject likely was air stacking. Ptm measurements of CVP and Ppao would be very misleading without Peso. Double arrow indicates the change $(\Delta)$ in Peso from the baseline value. Peso is measured with a fluid-filled catheter so that only the $\Delta$ Peso is used. All changes are relative to the values shown in $\mathbf{a}$

structures, and thus the value measured inside the vessel relative to Patm is no longer the Ptm.

Measurements of respiratory variations in $\mathrm{P}_{\mathrm{pl}}$ obtained by esophageal devices can be used to determine changes in Ptm of pulmonary vascular structures that occur during the respiratory cycle [26, 27]. Measurements are usually obtained at end-expiration because this usually is when $P_{p l}$ is closest to Patm. However, this may not be true when patients actively recruit expiratory muscles and increase $\mathrm{P}_{\mathrm{pl}}$ during expiration (Fig. 2), or when $\mathrm{P}_{\mathrm{pl}}$ is elevated by intrinsic or extrinsic PEEP. Failure to appreciate over-estimation of Ptm can lead to important management errors. For example, a central venous pressure of $20 \mathrm{mmHg}$ and a low cardiac output suggest depressed cardiac function, and diuresis or use of an inotrope is likely to be appropriate. However, if $\mathrm{P}_{\mathrm{pl}}$ is $20 \mathrm{mmHg}$ and the Ptm is actually zero, the patient needs volume and not an inotrope or diuretic.

Although transmural diastolic pressure of the right heart determines cardiac output, the directly measured 
value-and not Ptm-determines venous return. Thus, a central venous pressure elevated by PEEP reduces the gradient for venous return and cardiac output. Maintenance of cardiac output requires an increase in the upstream venous pressure by either a decrease in vascular capacitance or a fluid bolus [28]. However, there is a price to pay. The high venous pressure will increase capillary leak. Furthermore, when the patient is extubated and the positive $P_{p l}$ is removed, the gradient for venous return increases and the lungs can be flooded if the left ventricle cannot handle the increased volume [29].

On the left side of the heart, increasing $\mathrm{P}_{\mathrm{pl}}$ reduces the afterload on the left ventricle for the heart is effectively lifted relative to the systemic circulation [30]. This tends to increase cardiac output, but the benefit may be offset by a decrease in venous return due to the increase in $\mathrm{P}_{\mathrm{pl}}$. An inspiratory decrease in $\mathrm{P}_{\mathrm{pl}}$ adds an afterload to the left ventricle for the heart that is effectively lowered relative to the rest of the body $[31,32]$. This also increases venous return. If the swings are large enough or long enough, the rise in left ventricular filling pressure can produce pulmonary edema, especially when left ventricular function is poor.

In summary, changes in $\mathrm{P}_{\mathrm{pl}}$ during the respiratory cycle need to be considered when interpreting hemodynamic pressures. Interpretations are thus greatly benefitted with a simultaneous measurement of $\mathrm{P}_{\mathrm{pl}}$.

\section{Muscular pressure}

Effect of spontaneous breathing on transpulmonary pressure during assisted ventilation

Spontaneous breathing can offer protective effects to the injured lung: improved oxygenation and increased dorsal aeration/ventilation [33]. This results from the increase in $\mathrm{P}_{\mathrm{L}}$ obtained by lowering $\mathrm{P}_{\mathrm{pl}}\left(\mathrm{P}_{\mathrm{L}}=\mathrm{Paw}-\mathrm{P}_{\mathrm{pl}}\right)$ [32]. However, this protective role has generally been suggested in patients with less severe ARDS and modest spontaneous demands [34, 35]. Accumulating evidence indicates that spontaneous breathing might become deleterious in severe ARDS cases, as suggested by the beneficial effect of muscle paralysis observed in patients with severe ARDS $[35,36]$. First, $\mathrm{P}_{\mathrm{L}}$ calculated on Pes is likely to be injuriously high in severe ARDS, combined with the already high Paw and uncontrollable spontaneous demands [35]. In contrast, in less severe ARDS, Paw can be maintained at relatively low values, and spontaneous demands are often modest, thereby preventing injurious increases in $\mathrm{P}_{\mathrm{L}}$. Second, strenuous inspiratory efforts can shift air from non-dependent to dependent lung regions (i.e. pendelluft) even in the absence of large tidal volume and elevated Paw [37]. This occurs because the negative changes in $\mathrm{P}_{\mathrm{pl}}$ generated by diaphragmatic contraction have localized effects in dependent regions, and the
$\mathrm{P}_{\mathrm{pl}}$ changes are not uniformly transmitted (i.e. solid-like behavior). To this end, lung recruitment might improve the correlation between Pes and the true maximal $P_{\mathrm{L}}$ because it decreases atelectatic 'solid-like' regions.

Despite these limitations, monitoring Pes in ARDS patients with spontaneous inspiratory effort is highly relevant. First, $\mathrm{P}_{\mathrm{L}}$ calculated on Pes is a helpful measure for clinicians to detect the harm of spontaneous effort in severe ARDS, as suggested by large differences in $P_{L}$ between in mild and severe ARDS when spontaneous effort is preserved [35]. In this regard, even if no "safe" values for $\mathrm{P}_{\mathrm{L}}$ are reported, total end-inspiratory $\mathrm{P}_{\mathrm{L}}$ should probably be maintained below $20-25 \mathrm{cmH}_{2} \mathrm{O}$, which is known as the upper limit of physiological range [38]. Second, the intensity of pendelluft is proportional to the strength of the spontaneous effort (reflected by negative deflection of Pes) [37].

Finally, it is important to note that $\mathrm{P}_{\mathrm{L}}$ can be divided into two components: the resistive pressure, necessary to generate airflow between the airway and the alveoli, and transalveolar pressure, the pressure needed to expand the alveoli. Hence, only under static conditions (i.e. in the absence of flow) does $\mathrm{P}_{\mathrm{L}}$ equal the pressure distending the alveoli. Thus, unless mechanical properties change, $\mathrm{P}_{\mathrm{L}}$ should not differ between assisted and controlled ventilation for comparable tidal volumes and flows.

\section{Pes measurement to estimate respiratory muscle effort}

Contraction of the respiratory muscles generates a negative swing in $\mathrm{P}_{\mathrm{pl}}$, which can be assessed by changes in Pes (Fig. 3). The pressure generated by the respiratory muscles (Pmus) is computed as the difference between the static recoil pressure of the chest wall (Pcw,rel, obtained from Pes recordings under passive conditions) and the swing in Pes obtained under active conditions:

$$
\text { Pmus }=\text { Pcw, rel }- \text { Pes }
$$

The chest wall compliance (the passive volume/Pes relationship) can also be estimated from a theoretical value ( $4 \%$ of the predicted vital capacity per $\mathrm{cmH}_{2} \mathrm{O}$ ).

Values of Pmus between 5 and $10 \mathrm{cmH}_{2} \mathrm{O}$ can be considered, as a crude estimate, to be the desirable respiratory effort during partial ventilatory support [39]. The work of breathing (WOB) of the respiratory muscles corresponds to the integral of the product of Pmus and the generated volume, represented graphically by the Campbell diagram [40] (Fig. 3):

$$
\mathrm{WOB}=\int \text { Pmus } \cdot \mathrm{d} V
$$

WOB is expressed in joules and can be reported per liter or per minute. Normal values are around 0.35 and $2.4 \mathrm{~J} \mathrm{~min}^{-1}$, respectively [41]. WOB is computed based 


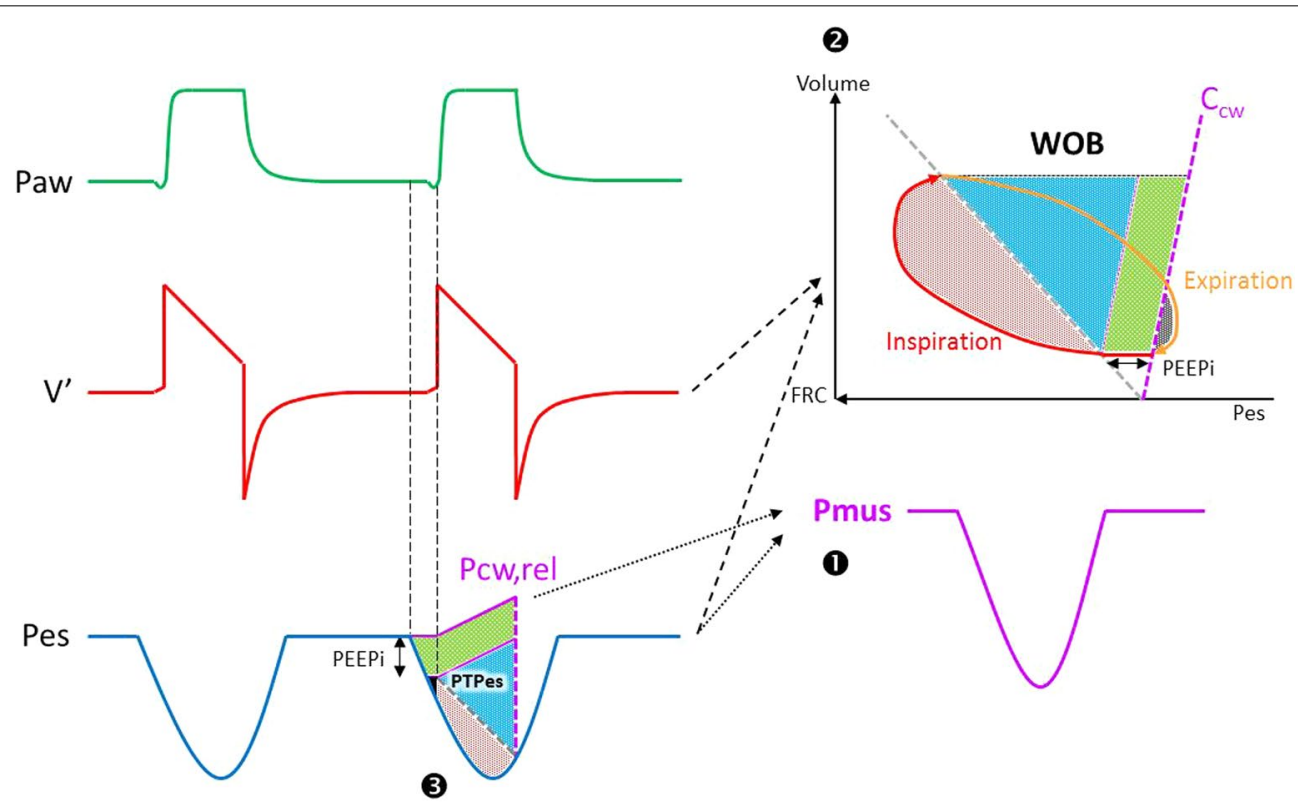

Fig. 3 Respiratory effort indices derived from the esophageal pressure analysis. The figure schematically represents airway pressure (Paw), flow ( $\left.V^{\prime}\right)$ and Pes of a patient with intrinsic PEEP (PEEPI) under pressure support ventilation. The static recoil pressure of the relaxed chest wall (PCw,rel), which represents the Pes that would be observed in passive conditions, has been superimposed to the Pes waveform. (1) The difference between Pcw,rel and Pmus corresponds to the muscle pressure developed by the respiratory muscles (Pmus). Campbell diagram: the work of breathing (WOB) is computed as the integral of the Pmus over the volume displaced. The chest wall compliance $(C \mathrm{CW})$ represents the value of the esophageal pressure when the muscles are relaxed and the volume passively insufflated above the functional residual capacity (FRC). Dashed gray line crosses the pressure-volume waveform at the zero-flow points. The pressure developed at the onset of the inspiratory effort without generating any volume represents the PEEPi. These landmarks unveil the different components of the WOB: resistive (red area), elastic (blue area), related to the PEEPi (green area) and related to active expiration (grey area). 3 The Pes pressure-time product (PTPes) corresponds to the area under the Pmus curve over the inspiratory time. The pressure developed between the start of the inspiratory effort and the onset of the inspiratory flow represents the amount of pressure needed to overcome the PEEPi. An additional pressure is dedicated to trigger the ventilator. The end of the active inspiratory muscle contraction occurred after the maximal negative value of the esophageal waveform and corresponds, in the case of ventilator cycling synchronization, to the onset of the expiration. In these conditions, relying the two points of zero-flow (dashed gray line) unveils the Pes related to the dynamic lung compliance. The PTPes can therefore be partitioned into the following parts: resistive (red area), elastic (blue area), related to the PEEPi (green area) and related to the inspiratory trigger (black area)

on volume displacement, and its value does not account for the duration of the respiratory effort and does not reflect the true energy expenditure of the respiratory muscles in the case of isometric effort.

The esophageal pressure-time product [42] (PTPes), which represents the integral of the Pmus curve over time, circumvents these limitations:

$$
\text { PTPes }=\int \text { Pmus } \cdot \mathrm{d} t
$$

PTPes is well correlated with the energy expenditure and oxygen consumption of the respiratory muscles. Normal values can be estimated to be between 50 and $150 \mathrm{cmH}_{2} \mathrm{O} \mathrm{s} \mathrm{min}{ }^{-1}$ [40]. Proper measurements of both WOB and PTPes take into account the presence of intrinsic PEEP [43].

Non-invasive estimates of respiratory effort may be useful at the bedside. In patients who are assisted with proportional assist ventilation mode, the Pmus value can be estimated from the value of the Paw and the gain set by the clinician [39].

Clinical applications Clinicians may be interested in estimating respiratory muscle effort for several reasons. First, in the context of hemodynamic shock, respiratory muscle effort may account for a significant proportion of total body oxygen consumption, thereby limiting oxygen delivery to vital organs [44]. Ensuring adequate ventilation and sedation by monitoring respiratory muscle effort may help to optimize the distribution of oxygen delivery. Second, insufficient and (possibly) excessive levels of inspiratory effort during ventilation can injure the diaphragm [45-49]. Titrating ventilation support to achieve near normal levels of inspiratory effort may prevent diaphragm injury and accelerate liberation from ventilation. Third, monitoring inspiratory effort may help clinicians to recognize potentially injurious patterns in patients with ARDS receiving partially assisted ventilation, both 
for the lungs and for the diaphragm [37]. The relevance of monitoring inspiratory effort during weaning trials is discussed in the section "Pes monitoring during weaning from mechanical ventilation" of this review.

\section{Patient-ventilator asynchrony and the role of Pes monitoring}

Mechanical ventilation, for the main part, is used as partial ventilatory support in situations where both the patient and the ventilator work together. Ideally, the ventilator settings should be adjusted to maintain a normal level of respiratory muscle activity and harmonious patient-ventilator interaction. Patient-ventilator asynchrony, which can be defined as a time mismatch between patient's effort and the ventilator breath duration, often occurs during assisted modes of ventilation and but is unrecognized. Many studies have demonstrated that major asynchrony is a common occurrence (at least $25 \%$ of the patients) throughout the course of ventilation [50-52]. Thille et al. [52] demonstrated that asynchrony occurred during both assist-control and pressure support ventilation and that it was associated with a longer duration of ventilation in patients who had an asynchrony index indicating $>10 \%$ of completely asynchronous breaths [7.5 (interquartile range 3-20) vs. 25.5 (9.5-42.5) days]. An observational study in 50 patients by Blanch and colleagues [53] found that asynchrony was detected in all patients and in all ventilator modes. These authors reported that the mortality rates among patients in the Intensive Care Unit and hospital increased in patients who had high asynchrony index $(>10 \%)$; these patients also showed a trend toward longer duration of mechanical ventilation. Importantly, adjusting the ventilator settings can dramatically reduce asynchrony [54].

Detecting patient-ventilator asynchrony on the ventilator display without recording respiratory muscle activity is, however, not always easy and can be missed even by experts [55]. This difficulty justifies attempts to develop automated systems $[56,57]$ or to use an esophageal signal, such as the electrical activity of the diaphragm (EAdi) [58] or the Pes. The Pes recording can detect asynchrony by comparing the time occurrence of the changes in Pes with those of Paw and flow-time waveforms (Fig. 4). The major groups of asynchrony can be classified according to the phase of respiration as (1) trigger asynchrony, (2) cycling asynchrony and (3) flow delivery mismatch.

\section{Trigger asynchrony}

1. Ineffective effort is recognized by a negative Pes swing without ventilator pressurization. It occurs in situations combining auto PEEP and excessive ventilation, inducing low respiratory drive and low inspiratory muscle effort, and it can be aggravated by a poorly sensitive triggering system. It occurs frequently with pressure support ventilation and is associated with poor outcomes.

2. Double triggering is the occurrence of two consecutive triggered breaths separated by a very short expiratory time. It occurs when the neural inspiratory time (Ti) is longer than machine $\mathrm{Ti}$, usually in patients with a high respiratory drive.

3. Reverse triggering is a phenomenon of respiratory entrainment and defined as a muscular effort triggered by the ventilator, usually in highly sedated patients. It occurs during the insufflation phase or at the transition phase from mechanical inspiration to expiration and can then lead to double cycling [59].

4. Auto-triggering is defined as a cycle delivered by the ventilator without triggering by the patient. This type of asynchrony can be seen in case of circuit leaks or cardiac oscillations.

\section{Cycling asynchrony}

1. Premature cycling is defined as a cycle with the machine Ti shorter than the neural Ti.

2. Delayed cycling occurs when the machine $\mathrm{Ti}$ is longer than the neural $\mathrm{Ti}$

\section{Flow delivery mismatch}

1. Flow starvation occurs during volume control mode when the ventilator delivers a peak inspiratory flow that is lower than the patient's demand. This is not an asynchrony per se, but it usually requires a change in the settings.

Patient-ventilator asynchrony is common and is associated with poor clinical outcomes. Pes can be used to better detect asynchrony at the bedside and to adjust the ventilator settings accordingly. However, whether the asynchrony is an indicator of severity or constitutes a biomarker for another systemic feature that compromises patients' outcome warrants further investigation.

\section{Pes monitoring during weaning from mechanical ventilation}

The pathophysiology of weaning research has demonstrated that respiratory effort changes progressively as patients fail a weaning trial $[60,61]$. During a trial of unassisted breathing, PTPes remained unchanged in patients who were successfully weaned from mechanical ventilation. In contrast, PTPes increased in patients who failed weaning because the mechanical load (resistive, elastic, and intrinsic-PEEP components) on the respiratory muscles increased [60,62]. When the dominant functional abnormality was investigated in 17 patients who failed to be weaned, ten had worsening mechanics and muscle 

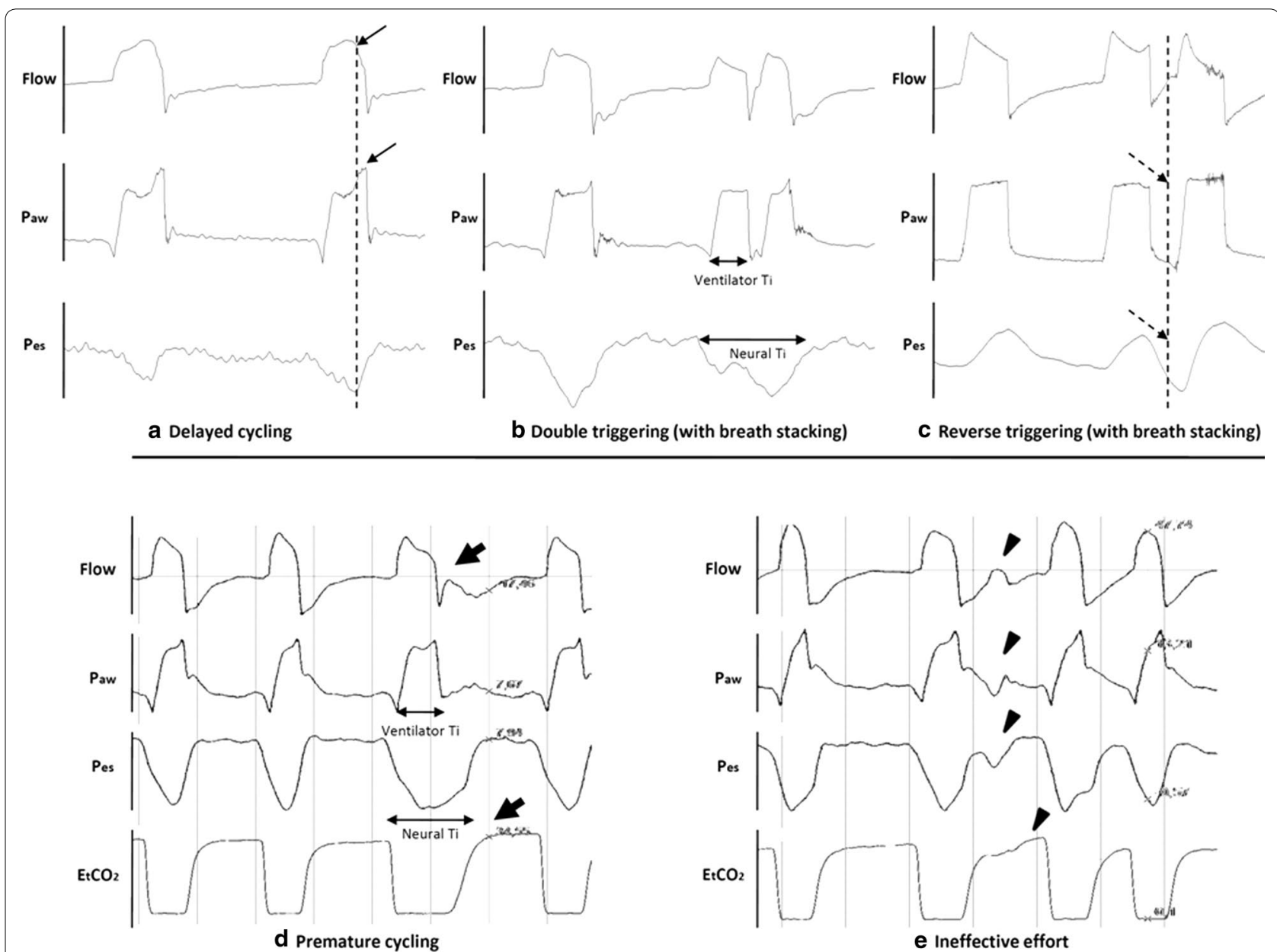

Fig. 4 Esophageal pressure monitoring to diagnose patient-ventilator asynchrony. Tracings of airflow (Flow), Paw, Pes, and end-tidal carbon dioxide $\left(E t \mathrm{CO}_{2}\right)$ in patients receiving mechanical ventilation. a Delayed cycling: an increase in Paw and a sharp decrease in flow (arrows) were observed due to abrupt relaxation of inspiratory muscles at the end of inspiration (dashed vertical line). $\mathbf{b}$ Double triggering the ventilator delivered two consecutive triggered breaths, whereas only one inspiratory effort determined by Pes was observed. c Reverse triggering: the reverse triggered breath (dashed arrow line) occurred following the machine breath, demonstrating positive deflection of Pes followed by negative deflection of Pes (dashed vertical line). d Premature cycling: Pes revealed the mismatch between neural inspiratory time ( $T i$ ) and ventilator Ti (neural $\gg$ ventilator Ti), resulting in amputation of the peak expiratory flow and an increase in $\mathrm{EtCO}_{2}$ due to prolonged Ti (thick arrows). e Ineffective effort: patient's inspiratory effort (small negative deflection of Pes) was observed but it was not sufficiently strong to trigger the ventilator; consequently, a distortion of airflow and Paw and an increase in $\mathrm{EtCO}_{2}$ were observed (arrowheads)

function, and four had blood gas abnormalities; failure in weaning could not be explained by functional abnormalities in the remaining three patients, suggesting that behavioral factors may have contributed to this failure [60].

The practice of medicine, though based on scientific knowledge, is centered on individualized care. The physician's primary task is to figure out how scientific principles apply to one particular patient. By inserting an esophageal catheter in a difficult-to-wean patient, a clinician can determine whether worsening mechanics (most common cause) was responsible for weaning failure, and then take the necessary steps to correct the problem. If an increase in resistive work occurred during a failed trial, then the management plan would focus on decreasing airway resistance by using bronchodilators and frequent suctioning or diuretics if the increase in resistance was due to bronchial edema. An increase in the elastic load could indicate that subclinical cardiogenic pulmonary edema may have been responsible for the failed trial (ESM Fig. 2). Indeed, pathophysiological studies have shown that cardiac performance worsens during weaning failure as a result of an increase in left ventricular afterload, which, in turn, is due to more negative swings in Pes [29, 63, 64].

Jubran et al. [65] showed that throughout a failed weaning trial, swings in Pes showed greater changes than the 


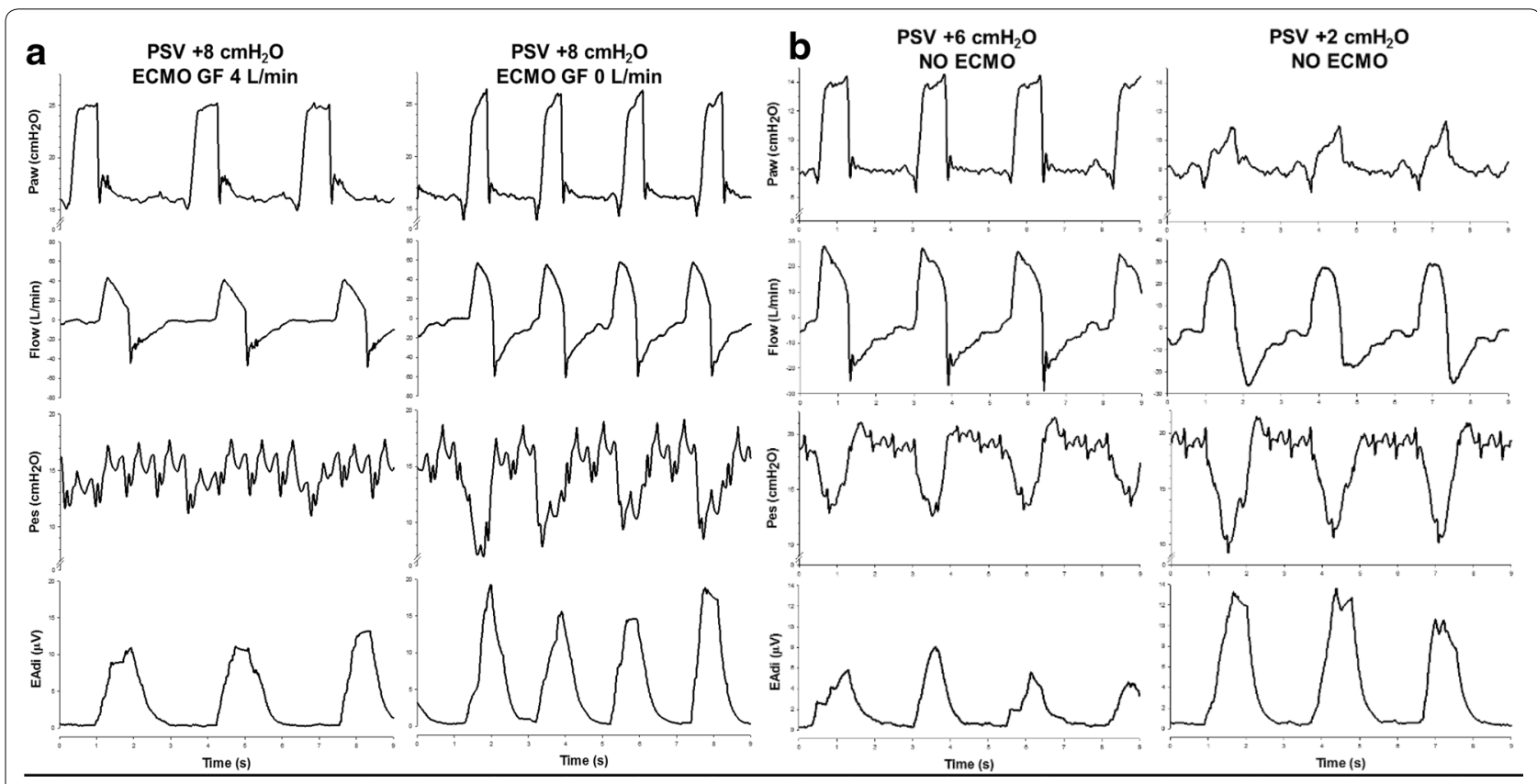

Fig. 5 Clinical validation of the correlation between electrical activity of the diaphragm (EAdi) and Pes swings at different levels of respiratory support. In two representative ARDS patients, amplitude of Pes swings and peak EAdi values increased by the same magnitude (right side of each panel) when: $\mathbf{a}$ the amount of $\mathrm{CO}_{2}$ removed by the extracorporeal membrane oxygenation (ECMO) system decreased by the reduction of sweep gas flow $(G F)$, without change in pressure support; $\mathbf{b}$ the pressure support level delivered by the ventilator was reduced. PSV Pressure support ventilation

rapid shallow breathing index $\left(f / \mathrm{V}_{\mathrm{T}}\right)$. Accordingly, monitoring of Pes throughout a weaning trial may provide additional guidance over a single measurement and, thus, may enhance the predication of weaning success/failure. When the change in Pes was quantified, the Pes trend index was more accurate in predicting weaning outcome than first-minute measurements of either Pes swings or $f /$ $\mathrm{V}_{\mathrm{T}}$ [65]. If these results can be confirmed, the Pes trend index could provide a useful monitoring tool during weaning. Moreover, increases in Pes swings during the trial could alert a physician to institute therapy, such as bronchodilators, vasodilators or diuretics, at a time that might convert an unsuccessful trial into a successful one.

\section{The correlation between diaphragm electrical activity and Pes swings}

Obtaining reliable Pes measurements can sometimes be challenging, and the question of using other physiological signals to obtain similar information becomes relevant. The electrical activity of the diaphragm (EAdi), a direct expression of neural inspiratory activity, can be recorded in daily clinical practice by a nasogastric tube connected to a ventilator and equipped with electrodes [66]. EAdi could theoretically be used as an alternative to Pes to estimate inspiratory demand. Studies focusing on this issue have shown a tight correlation between EAdi and transdiaphragmatic pressure (Pdi) in healthy volunteers and obstructive patients at rest, even in the presence of increased inspiratory flow rates or lung volumes [67-69]. EAdi and Pdi were also shown to be correlated and to be changed by the same magnitude during pressure support ventilation in a population of intubated patients suffering from acute respiratory failure when the level of assistance was increased [70]. The drops in both EAdi and Pes associated to external ventilatory assistance have also been correlated (Fig. 5) [71]. On the contrary, EAdi and Pdi amplitudes were found to be poorly correlated in patients with chronic obstructive pulmonary disease during incremental exercise [72], probably due to decreased neuro-muscular coupling in the presence of air trapping. In addition, it has been reported that the correlation factor (i.e. the slope of the linear correlation graph) between Pdi and EAdi differs between subjects, with one of the main reasons being individual anatomy [69]. Thus, EAdi amplitude can differ between subjects with similar inspiratory demand and requires calibration for interindividual comparisons-for example, by dividing measured EAdi amplitude by the EAdi amplitude obtained during maximal voluntary inspiratory effort [69]. Two alternative calibration procedures that can be used for intubated patients with acute respiratory failure have recently been published [73, 74]. One of these, the Pmus/ EAdi index (PEI), is measured during end-expiratory occlusion as the drop in Paw divided by the EAdi needed 
to generate it. By multiplying peak EAdi values by PEI, it is possible to calculate the absolute values of a patient's inspiratory effort. The second procedure is the patientventilator breath contribution index [74], defined as the ratio between tidal volume and EAdi during an assisted breath divided by the same ratio measured during a subsequent unexpected non-assisted one. The correlation between the patient-ventilator breath contribution index and the $\Delta$ Pes swings/ $\triangle$ PTPes ratio is significant. These two calibration approaches to compare absolute values of a patient's effort obtained from EAdi require further validation. It is also important to note that EAdi amplitude can be influenced by other factors, such as sedation [75] and clinical evolution [74].

EAdi can also be used to accurately monitor patientventilator synchrony $[55,75,76]$. Finally, as the EAdi value recorded at the onset of the inspiratory flow (autoEAdi) is tightly correlated with the patient's auto-PEEP, as measured by Pes [77], EAdi can also be used to estimate auto-PEEP.

EAdi provides alternative and complementary information to Pes, but it cannot replace it. Thus, whether the practical advantages of using EAdi outweigh the additional information provided by Pes (e.g. $\mathrm{P}_{\mathrm{L}}$ ) must be decided on an individualized basis.

\section{Conclusions and perspectives}

The multiple applications already described support the notion that Pes monitoring is an essential tool for personalized medicine and for improving the capability of physicians to diagnose complex clinical conditions. The results of recent studies suggest that bedside decisions regarding ventilator settings, lung protection, sedation, paralysis, weaning or even hemodynamic support might radically change if it were possible to consider the information coming from Pes monitoring. Some technical aspects of Pes measurement will need further refinements (e.g., those involving quantitative measurements of the chest wall properties).

Both the approach of using absolute Pes values and the dynamic approach in which only the swings in Pes are quantified have shown promising results for ventilation adjustments $[12,20]$. While the direct absolute method is simpler and has been made more reliable through the use of newly developed catheters and accurate calibration procedures, the dynamic approach, by testing a volume change, might better unveil the pathophysiological characteristics of the respiratory system. However, both methods require a number of assumptions: for the absolute $\mathrm{P}_{\mathrm{L}}$, that end-expiratory Pes is equal to the end-expiratory $P_{\mathrm{pl}}$ and that negative values of end-expiratory absolute $\mathrm{P}_{\mathrm{L}}$ correspond to a tendency of the alveoli and/or small airways to collapse; for the dynamic approach (testing a volume change), that $\mathrm{P}_{\mathrm{pl}}$ is equal to zero at zero PEEP and that the $\mathrm{E}_{\mathrm{L}}$ and Ers behave linearly throughout different lung volumes. In fact, especially when exploring the upper limits of lung stress, the two approaches have been found to produce conflicting results.

Synchronization with ventilator signals, automatic filling and automatic in vivo calibration are future developments that may enable this technology to be introduced into the daily clinical routine. Meanwhile, many of the clinical applications described in this review, with most of them tracking negative swings in Pes, such as the monitoring of asynchrony, over-assistance, strenuous efforts or difficult weaning, have been extensively validated, indicating that clinicians and patients likely benefit from the availability of this technology in daily clinical practice.

\section{Electronic supplementary material}

The online version of this article (doi:10.1007/s00134-016-4400-x) contains supplementary material, which is available to authorized users.

\section{Author details}

${ }^{1}$ Department of Anesthesia, Critical Care and Emergency, Fondazione IRCCS Ca' Granda Ospedale Maggiore Policlinico, Milan, Italy. ${ }^{2}$ Department of Critical Care Medicine, Hospital for Sick Children, University of Toronto, Toronto, ON, Canada. ${ }^{3}$ Intensive Care Unit, Osaka University Hospital, Suita, Japan.

${ }^{4}$ Department of Anesthesia, Hospital for Sick Children, University of Toronto, Toronto, ON, Canada. ${ }^{5}$ Department of Health Science, University of MilanBicocca, Monza, MB, Italy. ${ }^{6}$ Department of Physiology, University of Toronto, Toronto, Canada. ${ }^{7}$ Division of Respirology, Department of Medicine,

University Health Network and Mount Sinai Hospital, Toronto, ON, Canada. ${ }^{8}$ DHU A-TVB, Service de Réanimation Médicale, CHU Henri Mondor, Assistance Publique-Hôpitaux de Paris, , Créteil, France. ${ }^{9}$ Groupe de recherche clinique CARMAS, Faculté de Médecine de Créteil, Université Paris Est Créteil, Créteil, France. ${ }^{10}$ Division of Respiratory Diseases and Tuberculosis, Department of Medicine, Faculty of Medicine, Siriraj Hospital, Bangkok, Thailand. ${ }^{11}$ Keenan Research Centre, Li Ka Shing Knowledge Institute, St. Michael's Hospital, Toronto, Canada. ${ }^{12}$ Interdepartmental Division of Critical Care Medicine, University of Toronto, Toronto, ON, Canada. ${ }^{13}$ Anesthesia and Intensive Care, Fondazione IRCCS Policlinico San Matteo, University of Pavia, Pavia, Italy.

${ }^{14}$ Dipartimento di Fisiopatologia Medico-Chirurgica e dei Trapianti, Università degli Studi di Milano, Milan, Italy. ${ }^{15}$ Adult Intensive Care and Burn Unit, University Hospital of Lausanne, Lausanne, Switzerland. ${ }^{16}$ Department of Medical Intensive Care, University Hospital of Angers, Angers, France. ${ }^{17}$ Dipartimento dell'Emergenza e Trapianti d'Organo (DETO), Sezione di Anestesiologia e Rianimazione, Università degli Studi di Bari "Aldo Moro", Bari, Italy. ${ }^{18}$ Division of Pulmonary and Critical Care Medicine, Edward Hines Jr., Veterans Affairs Hospital and Loyola University of Chicago Stritch School of Medicine, Hines, IL, USA. ${ }^{19}$ Department of Critical Care, McGill University Heath Centre, Glen Site Campus, Montreal, QC, Canada. ${ }^{20}$ Department of Anesthesia, Critical Care, and Pain Medicine, Beth Israel Deaconess Medical Center and Harvard Medical School, Boston, MA, USA. ${ }^{21}$ Institut de Investigació i Innovació Parc Taulí, CIBER Enfermedades Respiratorias, Critical Care Center, Parc Tauli Hospital Universitari, Universitat Autònoma de Barcelona, Sabadell, Spain.

${ }^{22}$ Pulmonary Division, Heart Institute (InCor), Hospital das Clínicas, University of São Paulo, São Paulo, Brazil. ${ }^{23}$ Servei de Medicina Intensiva, Hospital de Sant Pau, Barcelona, Spain

\section{Acknowledgments}

The PLeUral pressure working Group (PLUG) is part of the Acute Respiratory Failure Section of the European Society of Intensive Care Medicine (ESICM). The aims and members of the PLUG Working Group are listed in the ESM. We would like to thank all the members of the PLUG Working Group for their active participation. We also thank Mr. Guy François and the European Society 
of Intensive Care Medicine (ESICM) for their continuous support to the activities of the PLUG Working Group.

\section{Compliance with ethical standards}

\section{Fundings}

E. Goligher is supported by a Post-Doctoral Fellowship from the Canadian Institutes of Health Research and by ISCIII PI13/02204-FEDER, CIBER Enfermedades Respiratorias to L. Blanch; T. Yoshida is funded by a RESTRACOMP training award from the Research Institute of the Hospital for Sick Children, Toronto, ON, Canada. L. Brochard is the Keenan Chair in Critical Care and Acute Respiratory failure, Keenan Research Centre, Toronto.

\section{Conflicts of interest}

F. Mojoli, D. Chiumello and L. Gattinoni were involved in a University research spin-off for the development of Nutrivent [Sidam, Mirandola (MO), Italy]. L. Blanch is inventor of one Corporació Sanitaria Parc Taulí-owned U.S. patent (US Patent No. 12/538,940):"Method and system for managed related patient parameters provided by a monitoring device". L. Blanch owns stock options of BetterCare S.L., which is a research and development spin off of Corporació Sanitària Parc Tauli (Spain). Outside the submitted work, J. Mancebo reports grants from Covidien, non-financial support from Maquet and General Electric and personal fees from Covidien, Hamilton, Braun, Air-Liquide, Faron, and A-Lung. Outside the submitted work, L. Brochard reports grants from Covidien, Fisher Paykel, non-financial support from Maquet, Philips and General Electric and personal fees from Covidien and Maquet. All other authors declare that they do not have any conflicts of interest to declare.

\section{Received: 28 February 2016 Accepted: 17 May 2016}

\section{Published online: 22 June 2016}

\section{References}

1. Akoumianaki E, Maggiore SM, Valenza F et al (2014) The application of esophageal pressure measurement in patients with respiratory failure. Am J Respir Crit Care Med 189:520-531

2. Brochard $L$ (2014) Measurement of esophageal pressure at bedside: pros and cons. Curr Opin Crit Care 20:39-46

3. Milic-Emili J, Mead J, Turner JM, Glauser EM (1964) Improved technique for estimating pleural pressure from esophageal balloons. J Appl Physiol 19:207-211

4. Mojoli F, Chiumello D, Pozzi M et al (2015) Esophageal pressure measurements under different conditions of intrathoracic pressure. An in vitro study of second generation balloon catheters. Minerva Anestesiol 81(8):855-864

5. Walterspacher S, Isaak L, Guttmann J et al (2014) Assessing respiratory function depends on mechanical characteristics of balloon catheters. Respir Care 59:1345-1352

6. Mojoli F, lotti GA, Torriglia F et al (2016) In vivo calibration of esophageal pressure in the mechanically ventilated patient makes measurements reliable. Crit Care 20(1):98

7. Milic-Emili J, Mead J, Turner JM (1964) Topography of esophageal pressure as a function of posture in man. J Appl Physiol 19:212-216

8. Baydur A, Behrakis PK, Zin WA et al (1982) A simple method for assessing the validity of the esophageal balloon technique. Am Rev Respir Dis 126:788-791

9. Higgs BD, Behrakis PK, Bevan DR, Milic-Emili J (1983) Measurement of pleural pressure with esophageal balloon in anesthetized humans. Anesthesiology 59:340-343

10. Chiumello D, Consonni D, Coppola S et al (2016) The occlusion tests and end-expiratory esophageal pressure: measurements and comparison in controlled and assisted ventilation. Ann Intensive Care. 6(1):13

11. Niknam J, Chandra A, Adams AB, Nahum A, Ravenscraft SA, Marini JJ (1994) Effect of a nasogastric tube on esophageal pressure measurement in normal adults. Chest 106(1):137-141

12. Gattinoni L, Carlesso E, Cadringher P et al (2003) Physical and biological triggers of ventilator-induced lung injury and its prevention. Eur Respir J Suppl 47:15s-25s
13. Protti A, Andreis DT, Monti M et al (2013) Lung stress and strain during mechanical ventilation: any difference between statics and dynamics? Crit Care Med 41:1046-1055

14. Grasso S, Terragni P, Birocco A et al (2012) ECMO criteria for influenza A (H1N1)-associated ARDS: role of transpulmonary pressure. Intensive Care Med 38:395-403

15. Chiumello D, Carlesso E, Cadringher P et al (2008) Lung stress and strain during mechanical ventilation for acute respiratory distress syndrome. Am J Respir Crit Care Med 178:346-355

16. Moreira LF, Aires ST, Gobbi CF et al (1995) Respiratory system, lung, and chest wall mechanics after longitudinal laparotomy in rats. Eur Respir J 8:105-108

17. Protti A, Cressoni M, Santini A et al (2011) Lung stress and strain during mechanical ventilation: any safe threshold? Am J Respir Crit Care Med 183:1354-1362

18. Cressoni M, Cadringher P, Chiurazzi C et al (2014) Lung inhomogeneity in patients with acute respiratory distress syndrome. Am J Respir Crit Care Med 189(2):149-158

19. Washko GR, O'Donnell CR, Loring SH (2006) Volume-related and volumeindependent effects of posture on esophageal and transpulmonary pressures in healthy subjects. J Appl Physiol 100:753-758

20. Pelosi P, Goldner M, McKibben A et al (2001) Recruitment and derecruitment during acute respiratory failure: an experimental study. Am J Respir Crit Care Med 164:122-130

21. Slutsky AS, Ranieri VM (2013) Ventilator-induced lung injury. N Engl J Med 369:2126-2136

22. Talmor D, Sarge T, O'Donnell CR et al (2006) Esophageal and transpulmonary pressures in acute respiratory failure. Crit Care Med 34:1389-1394

23. Talmor D, Sarge T, Malhotra A et al (2008) Mechanical ventilation guided by esophageal pressure in acute lung injury. N Engl J Med 359:2095-2104

24. Loring SH, Pecchiari M, Della Valle P et al (2010) Maintaining end-expiratory transpulmonary pressure prevents worsening of ventilator-induced lung injury caused by chest wall constriction in surfactant-depleted rats. Crit Care Med 38:2358-2364

25. Magder S (2015) Invasive hemodynamic monitoring. Crit Care Clin 31:67-87

26. Jardin F, Farcot JC, Boisante L, Curien N, Margairaz A, Bourdarias JP (1981) Influence of positive end-expiratory pressure on left ventricular performance. N Engl J Med 304:387-392

27. Marini JJ, Culver BH, Butler J (1981) Mechanical effect of lung distention with positive pressure on cardiac function. Am Rev Respir Dis 124:382-386

28. Nanas S, Magder S (1992) Adaptations of the peripheral circulation to PEEP. Am Rev Respir Dis 146:688-693

29. Lemaire F, Teboul JL, Cinotti L et al (1988) Acute left ventricular dysfunction during unsuccessful weaning from mechanical ventilation. Anesthesiology 69:171-179

30. McGregor M (1979) Current concepts: pulsus paradoxus. N Engl J Med 301:480-482

31. Magder SA, Lichtenstein S, Adelman AG (1983) Effect of negative pleural pressure on left ventricular hemodynamics. Am J Cardiol 52:588-593

32. Buda AJ, Pinsky MR, Ingels NB et al (1979) Effect of intrathoracic pressure on left ventricular performance. N Engl J Med 301:453-459

33. Putensen C, Muders T, Varelmann D, Wrigge H (2006) The impact of spontaneous breathing during mechanical ventilation. Curr Opin Crit Care 12:13-18

34. Putensen C, Zech S, Wrigge $\mathrm{H}$ et al (2001) Long-term effects of spontaneous breathing during ventilatory support in patients with acute lung injury. Am J Respir Crit Care Med 164:43-49

35. Yoshida T, Uchiyama A, Matsuura $\mathrm{N}$ et al (2013) The comparison of spontaneous breathing and muscle paralysis in two different severities of experimental lung injury. Crit Care Med 41:536-545

36. Papazian L, Forel J-M, Gacouin A et al (2010) Neuromuscular blockers in early acute respiratory distress syndrome. N Engl J Med 363:1 107-1116

37. Yoshida T, Torsani V, Gomes $S$ et al (2013) Spontaneous effort causes occult pendelluft during mechanical ventilation. Am J Respir Crit Care Med 188:1420-1427

38. Colebatch HJ, Greaves IA, Ng CK (1979) Exponential analysis of elastic recoil and aging in healthy males and females. J Appl Physiol 47:683-691 
39. Carteaux G, Mancebo J, Mercat A et al (2013) Bedside adjustment of proportional assist ventilation to target a predefined range of respiratory effort. Crit Care Med 41:2125-2132

40. Mead J, Smith JC, Loring SH (1985) Volume displacements of the chest wall and their mechanical significance. In: Roussos C, Macklem PT (eds) The thorax: Part A. M Dekker, New York, pp 369-392

41. Mancebo J, Isabey D, Lorino H et al (1995) Comparative effects of pressure support ventilation and intermittent positive pressure breathing (IPPB) in non-intubated healthy subjects. Eur Respir J 8:1901-1909

42. Sassoon CS, Light RW, Lodia R et al (1991) Pressure-time product during continuous positive airway pressure, pressure support ventilation, and T-piece during weaning from mechanical ventilation. Am Rev Respir Dis 143:469-475

43. Lessard MR, Lofaso F, Brochard L (1995) Expiratory muscle activity increases intrinsic positive end-expiratory pressure independently of dynamic hyperinflation in mechanically ventilated patients. Am J Respir Crit Care Med 151:562-569

44. Hussain SN, Graham R, Rutledge F, Roussos C (1986) Respiratory muscle energetics during endotoxic shock in dogs. J Appl Physiol 60:486-493

45. Goligher EC, Fan E, Herridge MS et al (2015) Evolution of diaphragm thickness during mechanical ventilation. Impact of inspiratory effort. Am J Respir Crit Care Med 192:1080-1088

46. Levine S, Nguyen T, Taylor N et al (2008) Rapid disuse atrophy of diaphragm fibers in mechanically ventilated humans. N Engl J Med 358:1327-1335

47. Reid WD, Belcastro AN (2000) Time course of diaphragm injury and calpain activity during resistive loading. Am J Respir Crit Care Med 162:1801-1806

48. Orozco-Levi M, Lloreta J, Minguella J, Serrano S, Broquetas JM, Gea J (2001) Injury of the human diaphragm associated with exertion and chronic obstructive pulmonary disease. Am J Respir Crit Care Med 164:1734-1739

49. Ebihara S, Hussain SN, Danialou G, Cho WK, Gottfried SB, Petrof BJ (2002) Mechanical ventilation protects against diaphragm injury in sepsis: interaction of oxidative and mechanical stresses. Am J Respir Crit Care Med 165(2):221-228

50. Chao DC, Scheinhorn DJ, Stearn-Hassenpflug M (1997) Patient-ventilator trigger asynchrony in prolonged mechanical ventilation. Chest 112:1592-1599

51. de Wit M, Miller KB, Green DA et al (2009) Ineffective triggering predicts increased duration of mechanical ventilation. Crit Care Med 37:2740-2745

52. Thille AW, Rodriguez P, Cabello B et al (2006) Patient-ventilator asynchrony during assisted mechanical ventilation. Intensive Care Med 32:1515-1522

53. Blanch L, Villagra A, Sales B et al (2015) Asynchronies during mechanical ventilation are associated with mortality. Intensive Care Med 41:633-64

54. Thille AW, Cabello B, Galia F et al (2008) Reduction of patient-ventilator asynchrony by reducing tidal volume during pressure-support ventilation. Intensive Care Med 34:1477-1486

55. Colombo D, Cammarota G, Alemani M et al (2011) Efficacy of ventilator waveforms observation in detecting patient-ventilator asynchrony. Crit Care Med 39:2452-2457

56. Younes M, Brochard L, Grasso S et al (2007) A method for monitoring and improving patient:ventilator interaction. Intensive Care Med 33:1337-1346

57. Blanch L, Sales B, Montanya J et al (2012) Validation of the Better Care ${ }^{\circledR}$ system to detect ineffective efforts during expiration in mechanically ventilated patients: a pilot study. Intensive Care Med 38:772-780

58. Sinderby C, Liu S, Colombo D et al (2013) An automated and standardized neural index to quantify patient-ventilator interaction. Crit Care $17 \cdot R 239$
59. Akoumianaki E, Lyazidi A, Rey N et al (2013) Mechanical ventilationinduced reverse-triggered breaths: a frequently unrecognized form of neuromechanical coupling. Chest 143:927-938

60. Jubran A, Tobin MJ (1997) Pathophysiologic basis of acute respiratory distress in patients who fail a trial of weaning from mechanical ventilation. Am J Respir Crit Care Med 155:906-915

61. Tobin MJ, Laghi F, Jubran A (2012) Ventilatory failure, ventilator support, and ventilator weaning. Compr Physiol 2:2871-2921

62. Laghi F, Cattapan SE, Jubran A et al (2003) Is weaning failure caused by low-frequency fatigue of the diaphragm? Am J Respir Crit Care Med 167:120-127

63. Jubran A, Mathru M, Dries D, Tobin MJ (1998) Continuous recordings of mixed venous oxygen saturation during weaning from mechanical ventilation and the ramifications thereof. Am J Respir Crit Care Med 158:1763-1769

64. Cabello B, Thille AW, Roche-Campo F et al (2010) Physiological comparison of three spontaneous breathing trials in difficult-to-wean patients. Intensive Care Med 36:1171-1179

65. Jubran A, Grant BJB, Laghi F et al (2005) Weaning prediction: esophageal pressure monitoring complements readiness testing. Am J Respir Crit Care Med 171:1252-1259

66. Sinderby C, Navalesi P, Beck J et al (1999) Neural control of mechanical ventilation in respiratory failure. Nat Med 5:1433-1436

67. Beck J, Sinderby C, Lindström L, Grassino A (1998) Crural diaphragm activation during dynamic contractions at various inspiratory flow rates. J Appl Physiol 85:451-458

68. Beck J, Sinderby C, Lindström L, Grassino A (1998) Effects of lung volume on diaphragm EMG signal strength during voluntary contractions. J Appl Physiol 85:1123-1134

69. Sinderby C, Beck J, Spahija J et al (1998) Voluntary activation of the human diaphragm in health and disease. J Appl Physiol 85:2146-2158

70. Beck J, Gottfried SB, Navalesi P et al (2001) Electrical activity of the diaphragm during pressure support ventilation in acute respiratory failure. Am J Respir Crit Care Med 164:419-424

71. Mauri T, Grasselli G, Suriano G et al (2016) Control of respiratory drive and effort in extracorporeal membrane oxygenation patients recovering from severe acute respiratory distress syndrome. Anesthesiology. doi:10.1097/ ALN.0000000000001103

72. Sinderby C, Spahija J, Beck J et al (2001) Diaphragm activation during exercise in chronic obstructive pulmonary disease. Am J Respir Crit Care Med 163:1637-1641

73. Bellani G, Mauri T, Coppadoro A et al (2013) Estimation of patient's inspiratory effort from the electrical activity of the diaphragm. Crit Care Med 41:1483-1491

74. Liu L, Liu S, Xie J et al (2015) Assessment of patient-ventilator breath contribution during neurally adjusted ventilatory assist in patients with acute respiratory failure. Crit Care 19:43

75. Vaschetto R, Cammarota G, Colombo D et al (2014) Effects of propofol on patient-ventilator synchrony and interaction during pressure support ventilation and neurally adjusted ventilatory assist. Crit Care Med 42:74-82

76. Mauri T, Bellani G, Foti G et al (2011) Successful use of neurally adjusted ventilatory assist in a patient with extremely low respiratory system compliance undergoing ECMO. Intensive Care Med 37(1):166-167

77. Bellani G, Coppadoro A, Patroniti N et al (2014) Clinical assessment of auto-positive end-expiratory pressure by diaphragmatic electrical activity during pressure support and neurally adjusted ventilatory assist. Anesthesiology 121:563-571 